\title{
Quantification of a Glucocorticoid Profile in Non-pooled Samples Is Pivotal in Stress Research Across Vertebrates
}

OPEN ACCESS

Edited by:

Lluis Tort,

Autonomous University of Barcelona,

Spain

Reviewed by:

Pierre J. Deviche,

Arizona State University, United States

Asta Tvarijonaviciute,

Universidad de Murcia, Spain

*Correspondence:

Johan Aerts

johan.aerts@ugent.be

Specialty section:

This article was submitted to Experimental Endocrinology,

a section of the journal

Frontiers in Endocrinology

Received: 25 May 2018 Accepted: 05 October 2018

Published: 23 October 2018

Citation:

Aerts J (2018) Quantification of a Glucocorticoid Profile in Non-pooled Samples Is Pivotal in Stress Research Across Vertebrates.

Front. Endocrinol. 9:635. doi: 10.3389/fendo.2018.00635

\begin{abstract}
Johan Aerts ${ }^{1,2 *}$
${ }^{1}$ Stress Physiology Research Group, Faculty of Pharmaceutical Sciences, Ghent University, Ostend, Belgium, ${ }^{2}$ Stress Physiology Research Group, Animal Sciences Unit, Flanders Research Institute for Agriculture, Fisheries and Food, Ostend, Belgium
\end{abstract}

Vertebrates are faced continuously with a variety of potential stressful stimuli and react by a highly conserved endocrine stress response. An immediate catecholamine mediated response increases plasma glucose levels in order to prepare the organism for the "fight or flight" reaction. In addition, in a matter of minutes after this (nor)adrenaline release, glucocorticoids, in particular cortisol or corticosterone depending on the species, are released through activation of the hypothalamic-pituitary-interrenal $(\mathrm{HPI})$ axis in fish or hypothalamic-pituitary-adrenal (HPA) axis in other vertebrates. These plasma glucocorticoids are well documented and widely used as biomarker for stress across vertebrates. In order to study the role of glucocorticoids in acute and chronic stress and gain in-depth insight in the stress axis (re)activity across vertebrates, it is pivotal to pin-point the involved molecules, to understand the mechanisms of how the latter are synthesized, regulated and excreted, and to grasp their actions on a plethora of biological processes. Furthermore, in-depth knowledge on the characteristics of the tissues as well as on the analytical methodologies available for glucocorticoid quantification is needed. This manuscript is to be situated in the multi-disciplinary research topic of glucocorticoid action across vertebrates which is linked to a wide range of research domains including but not limited to biochemistry, ecology, endocrinology, ethology, histology, immunology, morphology, physiology, and toxicology, and provides a solid base for all interested in stress, in particular glucocorticoid, related research. In this framework, internationally validated confirmation methods for quantification of a glucocorticoid profile comprising: (i) the dominant hormone; (ii) its direct precursors; (iii) its endogenously present phase I metabolites; and (iv) the most abundant more polar excreted exogenous phase I metabolites in non-pooled samples are pivotal. 


\section{KEY CONCEPTS}

\section{Accurate Identification and Quantification of Stressors Experienced by an Individual}

The sheer diversity in potential stressors, individual perception and subsequent reaction to these stressors, and the plethora of metabolic processes mediated by glucocorticoids render accurate identification and quantification of the stressors experienced by an individual pivotal.

\section{Analysis of the Dominant Glucocorticoid Is Affected by Other Steroids}

Glucocorticoid quantification can be biased by (i) the less dominant hormone; (ii) other steroids; (iii) direct precursors of the dominant hormone and the dominant hormone itself produced in extra-interrenal or extra-adrenal tissues; (iv) phase I metabolites present in the body; and (v) phase I metabolites present on the sample as contaminants.

\section{Analysis of the Dominant Glucocorticoid Is Affected by the Sample Tissue}

Results can be enhanced or suppressed by tissue specific compounds, and potential effects should be analytically validated.

\section{Analysis of the Dominant Glucocorticoid Is Affected by the Analytical Methodology Used}

Glucocorticoid analysis should best be performed using confirmation methods. Hereby, UPLC-MS/MS is considered the gold standard for quantitation of glucocorticoids in complex biological tissues as it has the needed sensitivity, selectivity and the advantage of having the capability to perform multi-analyte assays, even across compound classes.

\section{Analysis of the Dominant Glucocorticoid Is Affected by the Lack of Analytical Validation}

Methods should best be developed in an EN ISO/IEC 17025 regulated environment and analytically validated according the criteria of international standards to ensure full traceability and quality of the results in time.

\section{INTRODUCTION}

Moberg (1) defined stress as "a highly complex multidimensional phenomenon promoted by several noxious or unpredictable stimuli (stressors) that cause a physiological response (stress) aimed to maintain or recover the body homeostasis." Stressors are diverse and generally classified based on their: (i) type (i.e., chemical, physical, and psychological); (ii) duration [i.e., transitory (acute) or long-term (chronic)]; (iii) severity; (iv) (un)predictability; and (v) (un)controllability (2). Hereby, stress can be perceived as harmful or negative (distress), as well as a neutral or even as a positive condition (eustress) (3).

Organisms are faced continously with a variety of potential stressful stimuli and have developed over time a plethora of mechanisms to cope with changes and challenges in their environment (4). When faced with such stressful stimuli, vertebrates, ranging from fish to humans, react by a highly conserved endocrine stress response. An immediate catecholamine mediated response increases plasma glucose levels in order to prepare the organism for the "fight or flight" reaction (5). In addition, in a matter of minutes after this (nor)epinephrine [(nor)adrenaline] release, glucocorticoids, in particular cortisol $\left(11 \beta, 17 \alpha, 21\right.$-trihydroxypregn-4-ene-3,20-dione or $\left.\mathrm{C}_{21} \mathrm{H}_{30} \mathrm{O}_{5}\right)$ or corticosterone (11 $\beta, 21$-dihydroxypregn-4-ene-3,20-dione or $\mathrm{C}_{21} \mathrm{H}_{30} \mathrm{O}_{4}$ ) depending on the species, are released through activation of the hypothalamic-pituitary-interrenal (HPI) axis in fish (6) or hypothalamic-pituitary-adrenal (HPA) axis in other vertebrates (2). These plasma glucocorticoids are widely used as biomarker for stress across vertebrates $(7,8)$ and considered as adaptation hormones as they mediate a redistribution of energy (i.e., glucose) in order to restore pre-stress conditions. However, failure to regain homeostasis (maladaptation) will inevitably lead to chronic stress making the individual prone to the detrimental effects of glucocorticoid mediated actions (e.g., decreased growth, decreased reproduction, immune suppression, increased mortality). In the concept of "allostasis" [i.e., constancy through change by resetting the set-points for homeostasis in accordance to environmental cues $(9,10)]$, this situation can be described as: the transition from allostatic load (when the stress can be overcome, "eustress") to allostatic overload (when the stress cannot be overcome and becomes "distress") $(5,11)$. The dominant hormone, cortisol or corticosterone, respectively, is pleiotropic and affects all major homeostatic systems of the vertebrate's body. Besides modulating actions, which alter an organism's response to a stressor, also preparative actions, which alter the organism's response to a subsequent stressor or aid in adapting to a chronic stressor, are distinguished (2). Hereby, a plethora of physiological processes are modulated including central nervous system (CNS) and cardiovascular functions, the metabolic system [e.g., bone metabolism (12), stimulation of gluconeogenesis, proteolytic processes in the muscle and lipolysis in the adipose tissues to increase plasma glucose levels)], the immune system (inflammatory response and lymphocyte production), growth, reproduction, and behavior (13). Furthermore, physiological amounts of glucocorticoids are also essential for normal renal tubular function and thus for water and electrolyte homeostasis $(14,15)$.

The perception of potential stressors by an individual varies $(16,17)$ and depends on various factors including but not limited to the species, genetic background, previous experiences (18), gender (19), age, and types as well as duration of the stressors $(20,21)$. The stress response will vary accordingly between individuals and physiological and behavioral responses tend to be associated in distinct suites of correlated traits, called "stress coping styles" (22). Hereby, the proactive stress coping style (active coping or "fight-flight") is associated with low HPI or HPA axis responsiveness, but with high sympathetic reactivity, and is characterized by a high level of active avoidance, aggression and other actions indicating active attempts to counteract the stressful stimulus. The opposite is seen in reactive coping (passive coping or "conservation-withdrawal") (22). 
In all, the sheer diversity in potential stressors, individual perception and subsequent response to these stressors, and the plethora of metabolic processes mediated by glucocorticoids render accurate identification and quantification of the stressors experienced by an individual pivotal.

\section{ANALYSIS OF THE DOMINANT GLUCOCORTICOID IS AFFECTED BY OTHER STEROIDS}

\section{By the Less Dominant Glucocorticoid}

The vertebrate stress response is mediated by the stress system which is activated when encountering environmental stressors but also when the body is at rest, hereby responding to various signals (e.g., circadian, neurosensory, blood-borne, and limbic) (23). The noradrenergic synthesizing neurons of the locus coeruleus/norepinephrine-central sympathetic system in the brainstem as well as the corticosteroid releasing hormone $(\mathrm{CRH})$ and arginine vasopressin (AVP) synthesizing neurons of the hypothalamic paraventricular nuclei (PVN) comprise the central components, while the systemic sympathetic and adrenomedullary nervous systems and the HPI or HPA axis comprise the peripheral components of the stress system (24). Once triggered, CRH stimulates the release of adrenocorticotropic hormone (ACTH) from the pituitary, which results in glucocorticoid release, mainly cortisol, and corticosterone depending on the species, from the head kidney or adrenal gland, respectively. In ray-finned fish, cortisol predominates but corticosterone is also present; in the remaining fish species, the dominant or sole glucocorticoid varies. In this framework, 11-deoxycortisol in agnate fish (25); $1 \alpha$-hydroxycorticosterone in sharks and rays (26); and 11-deoxycorticosterone in teleost fish $(27,28)$, were shown to be active glucocorticoids. In amphibians, reptiles and birds, the dominant glucocorticoid is corticosterone, while mammals, most placentals and marsupials secrete primarily cortisol. However, some rodents (e.g., rats and mice) secrete primarily or only corticosterone, whereas most other rodents secrete primarily or only cortisol (e.g., guinea pigs), while hamsters secrete both glucocorticoids in equal quantities. As a consequence, the less dominant glucocorticoid should be considered during analytical validation as it can cause cross-reactivity and subsequently bias glucocorticoid quantification.

\section{By Other Steroids}

Glucocorticoids have a typical steroid structure consisting of a cyclopentaphenanthrene nucleus comprising three fused cyclohexane rings in a non-linear arrangement and a terminal cyclopentane ring. Most glucocorticoids possess a $\Delta 4$-3-keto group, a carbon ketol side-chain at $\mathrm{C}_{17}$ and generally an oxygen function at $\mathrm{C}_{11}$. The orientation of the groups attached to the steroid ring system is pivotal for the biological activity (29). As a consequence, other steroids including (i) androgens ( $\mathrm{C}_{19}$-steroids such as testosterone); (ii) estrogens $\left(\mathrm{C}_{18}\right.$-steroids such as estrone); (iii) mineralocorticoids ( $\mathrm{C}_{21}$-steroids such as aldosterone); and (iv) progestagens $\left(\mathrm{C}_{21}\right.$-steroids such as progesterone) (30), can be considered as physical-chemical similar molecules and should be taken into account during analytical validation as these compounds can cause crossreactivity and subsequently bias glucocorticoid quantification.

\section{By Direct Precursors of the Dominant Glucocorticoid and the Dominant Glucocorticoid Produced in "Extra-Interrenal" or "Extra-Adrenal" Tissues}

All steroids are derivatives of cholesterol $\left(\mathrm{C}_{27} \mathrm{H}_{46} \mathrm{O}\right)$ (31). Though, glucocorticoids were initially thought to be exclusively synthetized by the interrenal or adrenocortical cells, respectively, numerous studies have shown that they are also synthesized locally in so called "extra-interrenal" or "extra-adrenal" tissues (32). At present, these tissues include but are not limited to: primary lymphoid organs (33), intestine (34), CNS (35), cardiovascular system (36), skin (37-39), hair follicle (40), lung (41), kidney (42), and retina (43).

As a consequence, quantification of the dominant glucocorticoid produced by the HPI or HPA axis can be biased by direct precursors of the dominant hormone and the dominant hormone itself produced in extra-interrenal or extraadrenal tissues, making the quantification (or at least analytical validation) of these other glucocorticoids of importance.

\section{By the Manner How Glucocorticoids Are Regulated}

Systemically, glucocorticoid levels are influenced by distinct brain regions including structures of the limbic system (i.e., amygdala and hippocampus) and the midbrain (i.e., prefrontal cortex) (44) as well as by the hypothalamus, pituitary, and interrenal cells or adrenal cortex, respectively (45). In addition, the glucocorticoid pathway is controlled by the dominant glucocorticoid through a negative feedback loop. Besides this stress reactivity, glucocorticoid release is under control of a circadian clock (46). In humans the secretion of cortisol from the adrenal glands was shown to follow a diurnal cycle with a profound increase after awakening $(47,48)$.

Local regulation of glucocorticoid levels is mediated by access to target cells mediated by carrier proteins (49), by pre-receptor metabolism due to metabolic enzymes and by the availability of glucocorticoid (GR) and mineralocorticoid (MR) receptors.

\section{By the Non-free Dominant Glucocorticoid in the Blood}

Glucocorticoid levels vary rapidly due to the pulsatile nature of its secretion, rendering the dynamics of its binding critical determinants of tissue levels of free hormone and consequent hormone signaling. In most vertebrate species, the major proportion of circulating glucocorticoids are bound to a plasma glycoprotein called corticosteroid binding globulin (CBG) (50, 51). Subsequently, the free fraction is small (52). Since CBG is too large to leave the capillaries under normal circumstances, glucocorticoids bound to it remain in circulation. According to the "free hormone" hypothesis, it is the concentration of free, 
unbound hormone that determines how much glucocorticoids diffuses out of the capillaries and reaches the tissues. However, as CBG-bound glucocorticoids were shown to be released by enzymatic cleaving of the CBG molecule (53) and cell surface receptors for the CBG-glucocorticoid complex were shown to be present in certain tissues (54), one could argue that the glucocorticoid dissociation from CBG is part of the mechanism that makes the hormone biologically active.

In all, when focusing on cortisol producing vertebrates, cortisol is transported in blood more than $90 \%$ protein bound, approximately $70 \%$ with high affinity to CBG and $20 \%$ with low affinity to albumin, but it dissociates so rapidly that it is generally thought to be free (55). However, evidence indicates a dichotomous pattern with respect to CBG in these vertebrates: (i) a dominant branch where high levels of CBG bind most of the glucocorticoid which applies to the majority of vertebrates; and (ii) a smaller branch where low levels of CBG bind almost none of the glucocorticoid which applies to the fish (56). As a consequence, glucocorticoid analysis should be analytically validated to ensure that solely the free fraction of cortisol is quantified.

\section{By Phase I Metabolites of the Dominant Glucocorticoid Present in the Body}

Intracellular cortisol within the endoplasmatic reticulum of cells is regulated by local enzymes in a tissue-specific way independently of its plasma concentration (57). The intracellular

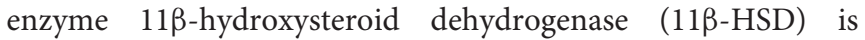
bidirectional (58): $11 \beta$-HSD type 1 is a reductase that converts the 11-keto metabolite cortisone to its active form 11-hydroxy cortisol, amplifying glucocorticoid action in liver and visceral adipose tissue, but also in brain, bone, gonad, muscle and other GR-expressing tissues including the eye, while $11 \beta$-HSD type 2 catalyzes the oxidation of cortisol to cortisone (a hydroxyl group at $\mathrm{C}_{11}$ becomes a carboxyl group) and is co-expressed with the MR in the kidney, colon and salivary gland and inactivates cortisol to cortisone, thereby enabling aldosterone to bind to the MR $(59,60)$. In addition, cortisone was found to be further reduced to $20 \beta$-hydroxycortisone by $20 \beta$-HSD type 2 (61). As a consequence, glucocorticoid analysis should include cortisone as the latter is rapidly interconverted to and from cortisol as well as 20ß-dihydrocortisone.

Corticosteroids affect a variety of target tissues over a broad range of time scales, ranging from slow gene transcription dependent to rapid gene transcription independent actions. Following uptake from the circulation, binding can occur by the two major functional groups of vertebrate corticosteroid receptors: GR and MR distinguished by their amino acid sequences and ligand specificity $(62,63)$. Most studies were performed on human intracellular genomic receptors [gGR reviewed by (64) and gMR reviewed by (65) as well as by (66)] regulating transcriptional activity of steroid target genes. Far less is known regarding the non-genomic effects mediated by the extracellular membrane glucocorticoid (mGR) and mineralocorticoid (mMR) receptors [for review see (67)], which allow rapid modulation of synaptic transmission and membrane ion currents hereby playing a key role in signal transduction at the synapse, the key neuron-to-neuron interface involved in learning and memory and as such in traumatic memories during times of stress $(68,69)$. As a consequence, glucocorticoid analysis should take into account the effect of phase I metabolites present in the body (i.e., cortisone and $20 \beta$-dihydrocortisone) as both compounds could potentially bind to GR and MR and are also excreted in minor proportions to the environment (see further).

\section{By Phase I Metabolites of the Dominant Glucocorticoid Present in the Environment}

The dominant glucocorticoid, cortisol or corticosterone, respectively, is controlled by the ratio of de novo synthesis to catabolism by the action of the respective enzymes involved. In this framework, steroids undergo extensive bio-transformations which decrease their biological activity and increase their water solubility by converting them to hydrophilic compounds that can be excreted. In general, these bio-transformations are divided into: (i) phase I metabolism which usually includes oxidation (e.g., hydroxylation) and/or reduction (e.g., hydrogenation) reactions; and (ii) phase II metabolism which usually involves conjugation reactions with polar groups such as glucuronide or sulfate and resulting into a highly hydrophilic product, which facilitates excretion in the urine or feces.

Cortisol and cortisone are metabolized in the liver (70). The main pathways of phase I metabolic reaction include: (i) oxidation and reduction at $\mathrm{C}_{11}$; (ii) reduction of the $\mathrm{C}_{4}-\mathrm{C}_{5}$ double bond; and (iii) reduction at $\mathrm{C}_{20}(30,71,72)$. In a next step, (allo)tetrahydrocortisol (THF) and (allo)-tetrahydrocortisone (THE) is (i) conjugated at a hydroxy group rapidly with glucuronic acid or sulfate and excreted in the urine or (ii) cleaved to the $\mathrm{C}_{19}$ steroids 11-hydroxy or 11-oxo-androsterone or etiocholanolone. In humans, non-metabolized cortisol and cortisone were shown to comprise only about $0.1 \%$ of the total urinary cortisol metabolites. At least $90 \%$ of the tetrahydro-derivatives of cortisol and cortisone are excreted into the urine as glucuronide or sulfate conjugates (73). Alternatively, reduction of the 20-oxo group by $20 \alpha$ - or 20 $\beta$-hydroxysteroid dehydrogenase yields $\alpha$ and $\beta$ cortols and cortolones, respectively, with subsequent oxidation at the $\mathrm{C}_{21}$ position to form the extremely polar metabolites, cortolic, and cortolonic acids (71). In addition, hydroxylation at $\mathrm{C}_{6}$ to form $6 \beta$-hydroxycortisol as well as reduction of the $\mathrm{C}_{20}$ position, which may occur without A ring reduction giving rise to $20 \alpha$ - and $20 \beta$-hydroxycortisol are described (74).

Overall, approximately $50 \%$ of secreted cortisol appears in the urine as THF/allo-THF/THE, 25\% as cortols/cortolones, $10 \%$ as $\mathrm{C}_{19} \mathrm{O}_{3}$ steroids (androstanes), and $10 \%$ appears as cortolic/cortolonic acids. The remaining 5\% metabolites are free, non-conjugated steroids (cortisol, cortisone and $6 \beta$ and $20 \alpha / 20 \beta$-metabolites of cortisol and cortisone). As a consequence, glucocorticoid analysis should include the most abundant phase I metabolites such as THF and THE as they are indicative for possible contamination of the sample with glucocorticoids from urine, feces, water, as well as from anthropogenic contamination (e.g., from hands). 


\section{ANALYSIS OF THE DOMINANT GLUCOCORTICOID IS AFFECTED BY THE TISSUE USED FOR GLUCOCORTICOID QUANTIFICATION}

The type of tissue used for glucocorticoid quantification is of utmost importance as each tissue incorporates glucocorticoids in accordance with the processes by which it is formed hereby defining the timeframe of interrenal or adrenocortical activity that the tissue represents. Subsequently, a proper tissue for chronic stress quantification should allow a retrospective (i.e., over a certain period of time) view of the stress axis activity, and subsequently should possess the capacity to incorporate glucocorticoids in a stress (i.e., in reaction to stress full stimuli eliciting a glucocorticoid mediated response) and time (i.e., over a certain period of time) dependent manner (75). The type of tissue also determines the structural changes of the dominant glucocorticoid that may occur via processes of conjugation to glucuronides and sulfates, metabolic conversion via enzymatic action and bacterial breakdown (8). As a consequence, the effect of the tissue on the analysis results, as the latter can be enhanced or suppressed by tissue specific compounds, should be analytically validated. In practice, the choice of tissue depends on various factors including but not limited to: (i) the species; (ii) the nature of the study; (iii) acute vs. chronic stress quantification; (iv) the tissues available for sampling; and (v) logistical feasibility. Table 1 provides an overview of the temporal window of stress axis (re)activation that is being reported in tissues commonly used for glucocorticoid analysis across vertebrates. Hereby, it should be noticed that at present no tissue for chronic stress quantification exists for amphibians.

\section{ANALYSIS OF THE DOMINANT GLUCOCORTICOID IS AFFECTED BY THE ANALYTICAL METHODOLOGY USED}

Glucocorticoids are measured using a wide variety of analytical methods including radio- (RIA) and enzyme

TABLE 1 | Tissues commonly used for glucocorticoid analysis across vertebrates.

\begin{tabular}{llc}
\hline Tissue & $\begin{array}{l}\text { Temporal window on } \\
\text { HPI/HPA (re)activity }\end{array}$ & References \\
\hline Vertebrate egg & Maternal deposition & $(76)$ \\
Vertebrate plasma/serum & Snapshot & $(57)$ \\
Whole body of fish larva & Snapshot & $(77)$ \\
Mammalian saliva & Minutes & $(78)$ \\
Vertebrate urine & Minutes to hours & $(72)$ \\
Vertebrate feces & Minutes to days & $(79)$ \\
Vertebrate excreta & Minutes to days & $(80)$ \\
Water & Minutes to days & $(81)$ \\
Reptilian shed skin & Weeks to months & $(82)$ \\
Avian feather & Weeks to months & $(83)$ \\
Fish scale & Weeks to years & $(75)$ \\
Mammalian hair & Weeks to years & $(84)$
\end{tabular}

(EIA) immunoassay, gas chromatography (GC), high performance liquid chromatography coupled to ultraviolet or fluorescence detection (HPLC-UV or FL), gas or liquid chromatography coupled to tandem mass spectrometry (GCor LC-MS/MS) as well as sensor based techniques. In practice, the technique of choice depends mainly on the availability of qualified operators and sophisticated equipment in the laboratory.

\section{By Screening Methods}

Immunoassays are most often chosen because they are fast, cheap, easy to perform, and commercially available for the dominant glucocorticoid in widely used tissues such as plasma of well-studied vertebrate species. RIA and EIA are both competitive binding assays necessitating an antibody directed against certain parts of the dominant glucocorticoid. While RIAs rely on a radioactive isotope (e.g., tritium or iodine) to generate a radioactive signal, EIAs use enzymes to generate a colorimetric signal to quantify the dominant glucocorticoid. Though immunoassays are sensitive (i.e., sufficient low levels can be detected) for the glucocorticoid of interest, major disadvantages are the lack of specificity (i.e., as they show high cross-reactivity with precursors and phase I metabolites of the targeted glucocorticoid as well as with substances with similar physical-chemical properties such as other steroids due to the poly-reactive nature of antibodies), the high lot-to-lot variation of antibodies (85), and the necessity to measure hormones individually. For example, Rettenbacher et al. (86) stated that their results for egg corticosterone could be explained by cross-reactions of the antibody used in the corticosterone EIA with other steroids, probably of gonadal origin as Hackl et al. (87) found a similar distribution pattern for progesterone. Subsequently, immunoassays should always be analytically validated in-depth.

The drawbacks of immunoassays have stimulated the development of new screening methods. Electrochemical biosensors have shown potential for fast, accurate and sensitive analysis of glucocorticoids. However, a continuing challenge is the sensitivity and stability of the surface bound biorecognition molecules, which depends on the matrix used for their immobilization on the sensor (88). Besides the use of antibodies, molecular imprinting, which involves the synthesis of polymers in the presence of a template to produce the complementary binding sites with specific recognition ability, is also used. During this formation, the functional monomers are polymerized in the presence of a template, which is subsequently removed by washing and/or extraction after polymerization, resulting in a molecularly imprinted polymer (MIP) (89). A library of cortisol-imprinted polymers was prepared by Baggiani et al. (90), while Moreno-Guzmán et al. (91) reviewed the existing immunosensors for human cortisol.

In all, the lack of or insufficient in-depth analytical validation is the main cause of inconsistent results generated by immunoassays in the pertinent literature. 


\section{By Confirmation Methods}

For confirmatory purposes, chromatographic techniques such as GC and LC, especially when coupled to (tandem) MS, are preferred since they allow a high resolution as required for complex biological tissues (92). Major disadvantages are the need for qualified operators and sophisticated equipment, high costs and complex sample preparations.

Significant improvement in the specificity of glucocorticoid measurements was achieved with the introduction of GCMS/MS, however, accurate quantification is limited to analytes which can be derivatized (93) in order to increase their volatility (94). Because of limited sensitivity, low throughput and laborintensive sample preparation, GC-MS/MS is not optimal for measuring glucocorticoid profiles. HPLC is well suited for the separation of glucocorticoids, though when coupled to UV or FL it lacks the sensitivity and specificity to distinguish glucocorticoid traces from the biological matrix background (29). Because of its inherent sensitivity and selectivity, LCMS/MS is considered the gold standard method for quantitation of glucocorticoids in complex biological tissues (92, 95, 96). It has the further advantage of having the capability to perform multi-compound assays, even across compound classes (97).

\section{ANALYSIS OF THE DOMINANT GLUCOCORTICOID IS AFFECTED BY THE LACK OF ANALYTICAL VALIDATION}

Overall, glucocorticoid levels to be quantified are considered "trace levels" as they are situated in the ppb $\left(\mu \mathrm{g} \mathrm{kg}^{-1}\right.$ or $\left.\mu \mathrm{g} \mathrm{L}^{-1}\right)$ and ppt (ng kg ${ }^{-1}$ or $\mathrm{ng} \mathrm{L}^{-1}$ ) range. Regardless the sample tissue and analytical methodology used, it is pivotal to demonstrate that results are accurate, precise, and not biased by interfering compounds rendering results highly reliable. Subsequently, every procedure [i.e., parameter(s)/tissue combination using a specific analytical methodology] should be analytically validated. In this framework, working according the criteria of international standards such as EN ISO/IEC 17025 (98) and Commission Decision No. 2002/657/EC (99, 100), whereby experiments are carried out by well trained and authorized personnel in a controlled environment are a must. Hereby, the use of calibrated equipment, products with a certificate of analysis as well as performing all tests in standardized conditions hereby registering all details in logbooks is of importance. In addition, determination of the performance characteristics such as accuracy, trueness, precision, sensitivity, specificity and crossreactivity with structurally related compounds are of utmost importance as they can influence the interpretation of results between studies. In particular immunoassays are prone to be biased by this as the used antiserum differs between assays leading to differences in cross-reactivity (8). Subsequent, physiological (i.e., by pharmacologically induced physiological changes in circulating glucocorticoid levels and to evaluate whether these changes are reflected in measured concentrations afterwards) as well as biological (i.e., glucocorticoid measurements in relation to cortical activity and the experience of stress) validation is needed in order to state that the method is fit for purpose (7).

As a consequence, one should try to use methods developed in an EN ISO/IEC 17025 regulated environment and analytically validated according the criteria of international standards as this ensures full traceability and quality of the results in time.

\section{CONCLUSION}

At present, most studies in the pertinent literature have focused on the quantification of the dominant glucocorticoid, cortisol or corticosterone depending on the species, using immunoassays. Hereby, one should bare in mind that: (i) results are prone to bias by cross-reactivity from other glucocorticoids as well as substances with similar physical-chemical properties, making analytical validation a must; (ii) immunoassays are screening methods which do not allow quantification of multiple substances, making them not suited for quantification of a glucocorticoid profile needed to obtain a more accurate and complete view on the HPI or HPA axis (re)activity, respectively. However, in-depth validated immunoassays for the dominant glucocorticoid can be useful in cases when only an indication (i.e., qualitative) of stress is needed. In addition, the use of pooled samples (e.g., for whole body of fish larva) renders it impossible to take into account the coping style of a single individual.

As a consequence, internationally validated confirmation methods for quantification of a glucocorticoid profile comprising: (i) the dominant hormone (e.g., cortisol); (ii) its direct precursors (i.e., $17 \alpha$-hydroxyprogesterone and 11deoxycortisol; as both will certainly lead to cortisol production); (iii) its endogenously present phase I metabolites (i.e., cortisone and $20 \beta$-dihydrocortisone; as feedback regulation of cortisol at pre-receptor level is mediated by $11 \beta$-HSD and $20 \beta$ reductase, respectively); and (iv) the most abundant more polar excreted phase I metabolites (i.e., tetrahydrocortisol and tetrahydrocortisone; to establish if exogenous glucocorticoids present in the environment (e.g., from water) or anthropogenic derived glucocorticoids (e.g., from hands) may have influenced the results) in non-pooled samples are pivotal in stress research across vertebrates.

\section{AUTHOR CONTRIBUTIONS}

The author confirms being the sole contributor of this work and has approved it for publication.

\section{ACKNOWLEDGMENTS}

JA would like to thank the Chief Editor of Frontiers in Endocrinology for the invitation. 


\section{REFERENCES}

1. Moberg GP. Biological response to stress: key assessment of animal wellbeing? In: Moberg GP editor. Animal Stress. Bethesda, MD: American Physiological Society publ (1996). p. 27-49.

2. Sapolsky RM, Romero LM, Munck AU. How do glucocorticoids influence stress responses? Integrating permissive, suppressive, stimulatory and preparative actions. Endocr Rev. (2000) 21:55-89. doi: 10.1210/er. 21.1.55

3. Webster AJF. Environmental stress and the physiology, performance and health of ruminants. J Anim Sci. (1983) 57:1584-93. doi: $10.2527 /$ jas $1983.5761584 \mathrm{x}$

4. Wingfield JC, Romero LM. Adrenocortical responses to stress and their modulation in free-living vertebrates. In: McEwen BS editor. Handbook of Physiology, Section 7: The Endocrine System. Coping With the Environment: Neural and Endocrine Mechanisms. Oxford: Oxford University Press (2001). p. 211-236.

5. Korte SM, Koolhaas JM, Wingfield JC, McEwen BS. The Darwinian concept of stress: benefits of allostasis and costs of allostatic load and the trade-offs in health and disease. Neurosci Biobehav Rev. (2005) 29:3-38. doi: 10.1016/j.neubiorev.2004.08.009

6. Wendelaar Bonga SE. The stress response in fish. Physiol Rev. (1997) 77:591-625. doi: 10.1152/physrev.1997.77.3.591

7. Lane J. Can non-invasive glucocorticoid measures be used as reliable indicators of stress in animals? Anim. Welfare (2006) 15:331-42.

8. Cook NJ. Review: minimally invasive sampling media and the measurement of corticosteroids as biomarkers of stress in animals. Can J Anim Sci. (2012) 92:227-59. doi: 10.4141/cjas2012-045

9. McEwen BS, Wingfield JC. The concept of allostasis in biology and biomedicine. Horm Behav. (2003) 43:2-15. doi: 10.1016/S0018-506X(02)00024-7

10. McEwen BS, Wingfield JC. What's in a name? Integrating homeostasis, allostasis and stress. Horm Behav. (2010) 57:1-16. doi: 10.1016/j.yhbeh.2009.09.011

11. Korte SM, Olivier B, Koolhaas JM. A new animal welfare concept based on allostasis. Physiol Behav. (2007) 92:422-8. doi: 10.1016/j.physbeh.2006.10.018

12. Canalis E, Delany AM. Mechanisms of glucocorticoid action in bone. Ann N Y Acad Sci. (2002) 966:73-81. doi: 10.1111/j.1749-6632.2002.tb04204.x

13. Goodman HM. Basic Medical Endocrinology, 4th ed. New York, NY: Academic Press (2009).

14. Chrousos GP. Stress and disorders of the stress system. Nat Rev Endocrinol. (2009) 5:374-81. doi: 10.1038/nrendo.2009.106

15. Papadimitriou A, Priftis KN. Regulation of the hypothalamicpituitary-adrenal axis. Neuroimmunomodulation (2009) 16:265-71. doi: $10.1159 / 000216184$

16. Baker MR, Gobush KS, Vynne $\mathrm{CH}$. Review of factors influencing stress hormones in fish and wildlife. J Nat Conserv. (2013) 21:309-18. doi: 10.1016/j.jnc.2013.03.003

17. Cockrem JF. Individual variation in glucocorticoid stress responses in animals. Gen Comp Endocrinol. (2013) 181:45-58. doi: 10.1016/j.ygcen.2012.11.025

18. De Carvalho Tifoli SM, Von Werne Baes C, Martins CMS, Juruena M. Early life stress, HPA axis, and depression. Psychol Neurosci. (2011) 4:229-34. doi: 10.3922/j.psns.2011.2.008

19. Kudielka BM, Kirschbaum C. Awakening cortisol responses are influenced by health status and awakening time but not by menstrual cycle phase. Psychoneuroendocrinology (2003) 28:35-47. doi: 10.1016/S0306-4530(02)00008-2

20. Barton B. A. Stress in fishes: a diversity of responses with particular reference to changes in circulating corticosteroids. Integr Comp Biol. (2002) 42:517-25. doi: $10.1093 / \mathrm{icb} / 42.3 .517$

21. Blas J, Bortolotti GR, Tella JL, Baos R, Marchant TA. Stress response during development predicts fitness in a wild, long lived vertebrate. Proc Natl Acad Sci USA. (2007) 104:8880-4. doi: 10.1073/pnas.0700232104

22. Øverli Ø, Sørensen C, Pulman KGT, Pottinger TG, Korzan W, Summers CHE, et al. Evolutionary background for stress coping styles: relationships between physiological, behavioural, and cognitive traits in nonmammalian vertebrates. Neurosci Biobehav Rev. (2007) 31:396-412. doi: 10.1016/j.neubiorev.2006.10.006

23. Dickerson SS, Kemeny ME. Acute stressors and cortisol responses: a theoretical integration and synthesis of laboratory research. Phychol Bull. (2004) 130:355-91. doi: 10.1037/0033-2909.130.3.355

24. Bonfiglio JJ, Inda C, Refojo D, Holsboer F, Arzt E, Silberstein S. The corticotropin-releasing hormone network and the hypothalamic pituitary-adrenal Axis: molecular and cellular mechanisms involved. Neuroendocrinology (2011) 94:12-20. doi: 10.1159/000328226

25. Close DA, Yuna S-S, McCormick SD, Wildbill AJ, Weiming L. 11Deoxycortisol is a corticosteroid hormone in the lamprey. Proc Natl Acad Sci USA. (2010) 107:13942-7. doi: 10.1073/pnas.0914026107

26. Anderson WG. The endocrinology of $1 \alpha$-hydroxycorticosterone in elasmobranch fish: a review. Comp Biochem Physiol A Mol Integr Physiol. (2012) 162:73-80. doi: 10.1016/j.cbpa.2011.08.015

27. Sturm A, Bury N, Dengreville L, Fagart J, Flouriot G, Rafestin-Oblin ME, et al. 11-Deoxycorticosterone is a potent agonist of the rainbow trout (Oncorhynchus mykiss) mineralocorticoid receptor. Endocrinology (2005) 146:47-55. doi: 10.1210/en.2004-0128

28. Mathieu C, Milla S, Mandiki SNM, Douxfils J, Douny C, Scippo ML, et al. First evidence of the possible implication of the 11-deoxycorticosterone (DOC) in immune activity of Eurasian perch (Perca fluviatilis, L.) comparison with cortisol. Comp Biochem Physiol A Molec Integrat Physiol. (2013) 165:149-59. doi: 10.1016/j.cbpa.2013.02.025

29. Volin P. High-performance liquid chromatographic analysis of corticosteroids. J Chrom B (1995) 671:319-40. doi: 10.1016/0378-4347(95)00259-L

30. Miller WL, Auchus RJ. The molecular biology, biochemistry, and physiology of human steroidogenesis and its disorders. Endocrine Rev. (2011) 32:81-151. doi: 10.1210/er.2010-0013

31. Acton S, Rigotti A, Landschulz KT, Xu S, Hobbs HH, Krieger M. Identification of scavenger receptor SR-BI as a high-density lipoprotein receptor. Science (1996) 27:518-20. doi: 10.1126/science.271.5248.518

32. Taves MD, Gomez-Sanchez CE, Soma KK. Extra-adrenal glucocorticoids and mineralocorticoids: evidence for local synthesis, regulation, and function. Am J Physiol Endocrinol Metab. (2011) 301:E11-24. doi: 10.1152/ajpendo.00100.2011

33. Vacchio MS, Papadopoulos V, Ashwell JD. Steroid production in the thymus: implications for thymocyte selection. J Exp Med. (1994) 179:1835-46. doi: $10.1084 /$ jem.179.6.1835

34. Keeney DS, Ikeda Y, Waterman MR, Parker KL. Cholesterol side chain cleavage cytochrome P450 gene expression in the primitive gut of the mouse embryo does not require steroidogenic factor 1. Mol Endocrinol. (1995) 9:1091-8.

35. Stromstedt M, Waterman MR. Messenger RNAs encoding steroidogenic enzymes are expressed in rodent brain. Mol Brain Res. (1995) 34:75-88. doi: 10.1016/0169-328X(95)00140-N

36. Hatakeyama H, Miyamori I, Takeda Y, Yamamoto H, Mabuchi H. The expression of steroidogenic enzyme genes in human vascular cells. Biochem Mol Biol Int. (1996) 40:639-45.

37. Slominski A, Wortsman J, Tuckey RC, Paus R. Differential expression of HPA axis homolog in the skin. Mol Cell Endocrinol. (2007) 265-266:143-9. doi: 10.1016/j.mce.2006.12.012

38. Cirillo N, Prime SS. Keratinocytes synthesize and activate cortisol. J Cell Biochem. (2011) 112:1499-505. doi: 10.1002/jcb.23081

39. Skobowiat C, Dowdy JC, Sayre RM, Tuckey RC, Slominsky A. Cutaneous hypothalamic-pituitary-adrenal axis homolog: regulation by ultraviolet radiation. Am J Physiol Endocrinol Metab. (2011) 301:E484-93. doi: 10.1152/ajpendo.00217.2011

40. Ito N, Ito T, Kromminga A, Bettermann A, Takigawa M, Kees F, et al. Human hair follicles display a functional equivalent of the hypothalamic-pituitaryadrenal (HPA) axis and synthesize cortisol. FASEB J. (2005) 19:1332-4. doi: 10.1096/fj.04-1968fje

41. Provost PR, Tremblay Y. Genes involved in the adrenal pathway of glucocorticoid synthesis are transiently expressed in the developing lung. Endocrinology (2005) 146:2239-45. doi: 10.1210/en.2005-0077 
42. Xue C, Siragy HM. Local renal aldosterone system and its regulation by salt, diabetes, and angiotensin II type 1 receptor. Hypertension (2005) 46:584-90. doi: 10.1161/01.HYP.0000175814.18550.c0

43. Zmijewski MA, Sharma RK, Slominski A. Expression of molecular equivalent of hypothalamic-pituitary-adrenal axis in adult retinal pigment epithelium. J Endocrinol. (2007) 193:157-69. doi: 10.1677/joe.1.06927

44. Herman JP, Ostrander MM, Mueller NK, Figueiredo H. Limbic system mechanisms of stress regulation: hypothalamo-pituitary-adrenocortical axis. Prog Neuropsychopharmacol Biol Psychiatr. (2005) 29:1201-13. doi: 10.1016/j.pnpbp.2005.08.006

45. Enyeart JJ. Biochemical and ionic signaling mechanisms for ACTHstimulated cortisol production. Vitam Horm. (2005) 70:265-79. doi: 10.1016/S0083-6729(05)70008-X

46. Chung S, Son GH, Kim K. Circadian rhythm of adrenal glucocorticoid: its regulation and clinical implications. Biochim Biophys Acta (2011) 1812:581-91. doi: 10.1016/j.bbadis.2011.02.003

47. Fries E, Dettenborn L, Kirschbaum C. The cortisol awakening response (CAR): facts and future directions. Int J Psychphysiol. (2009) 72:67-73. doi: 10.1016/j.ijpsycho.2008.03.014

48. Clow A, Huclebridge F, Stalder T, Evans P, Thorn L. The cortisol awakening response: more than a measure of HPA axis function. Neurosci Biobehav Rev. (2010) 35:97-103. doi: 10.1016/j.neubiorev.2009.12.011

49. Breuner CW, Orchinik M. Plasma binding proteins as mediators of corticosteroid action in vertebrates. J Endocrinol. (2002) 175:99-112. doi: 10.1677 /joe.0.1750099

50. Avvakumov GV. Structure and function of corticosteroid-binding globulin: role of carbohydrates. J Steroid Biochem Molec Biol. (1995) 53:515-22. doi: 10.1016/0960-0760(95)00099-L

51. Gardill BR, VoglMR, Lin HY, Hammond L, Muller YA. Corticosteroidbinding globulin: structure function implications from species differences. PLoS ONE (2012) 7:e52759. doi: 10.1371/journal.pone.0052759

52. Malisch JL, Breuner CW. Steroid-binding proteins and free steroids in birds. Mol Cell Edocrinol. (2010) 316:42-52. doi: 10.1016/j.mce.2009.09.019

53. Hammond GL. Potential functions of plasma steroidbinding proteins. Trends Endocrinol Metab. (1995) 6:298-304. doi: 10.1016/1043-2760(95)00162-X

54. Singer CJ, Khan MS, Rosner W. Characteristics of the binding of corticosteroid-binding globulin to rat cell membranes. Endocrinology (1988) 122:89-96. doi: 10.1210/endo-122-1-89

55. Pretorius CJ, Galligan JP, McWhinney BC, Briscoe SE, Ungerer JP. Free cortisol method comparison: ultrafiltration, equilibrium dialysis, tracer dilution, tandem mass spectrometry and calculated free cortisol. Clin Chim Acta (2011) 412:1043-7. doi: 10.1016/j.cca.2011.02.019

56. Desantis LM, Delehanty B, Weir JT, Boonstra R. Mediating free glucocorticoid levels in the blood of vertebrates: are corticosteroidbinding proteins always necessary? Funct Ecol. (2013) 27:107-19. doi: $10.1111 / 1365-2435.12038$

57. Gatti R, Antonelli G, Prearo M, Spinella P, Cappellin E, De Palo EF. Cortisol assays and diagnostic laboratory procedures in human biological fluids. Clin Biochem. (2009) 42:1205-17. doi: 10.1016/j.clinbiochem.2009.04.011

58. Chapman K, Holmes M, Seckl J. 11-beta-hydroxysteroid dehydrogenases: intracellular gate-keepers of tissue glucocorticoid action. Physiol Rev. (2013) 93:1139-206. doi: 10.1152/physrev.00020.2012

59. Walker BR. Extra-adrenal regeneration of glucocorticoids by $11 \beta$ hydroxysteroid dehydrogenase type 1: physiological regulator and pharmacological target for energy partitioning. Proc Nutr Soc. (2007) 66:1-8. doi: 10.1017/S002966510700523X

60. Zhou HY, Hu G-X, Lian QQ, Morris D, Ge RS. The metabolism of steroids, toxins and drugs by 11 beta-hydroxysteroid dehydrogenase 1. Toxicology (2012) 292:1-12. doi: 10.1016/j.tox.2011.11.012

61. Tokarz J, Norton W, Möller G, Hrabé de Angelis M, Adamski J. Zebrafish 20b-hydroxysteroid dehydrogenase type 2 is important for glucocorticoid catabolism in stress response. PLoS ONE (2013) 8:e54851. doi: 10.1371/journal.pone.0054851

62. Arriza JL, Weinberger C, Cerelli G, Glaser TM, Handellin BL, Houseman DE, et al. Cloning of human mineralocorticoid receptor complementary DNA: structural and functional kinship with the glucocorticoid receptor. Science (1987) 237:268-75. doi: 10.1126/science.3037703
63. Fuller PJ, Yao YZ, Yang J, Young MJ. Mechanisms of ligand specificity of the mineralocorticoid receptor. J Endocrinol. (2012) 213:15-24. doi: 10.1530/JOE-11-0372

64. Nicolaides NC, Galata Z, Kino T, Chrousos GP, Charmandari E. The human glucocorticoid receptor: molecular basis of biologic function. Steroids (2010) 75:1-12. doi: 10.1016/j.steroids.2009.09.002

65. Pippal JB, Fuller PJ. Structure-function relationships in the mineralocorticoid receptor. J Mol Endocrinol. (2008) 41:405-13. doi: 10.1677/JME-08-0093

66. Odermatt A, Atanasov AG. Mineralocorticoid receptors: emerging complexity and functional diversity. Steroids (2009) 74:163-71. doi: 10.1016/j.steroids.2008.10.010

67. Christ M, Haseroth K, Falkenstein E, Wehling M. Nongenomic steroid actions: fact or fancy? Vitam Horm. (1999) 57:325-73. doi: 10.1016/S0083-6729(08)60647-0

68. Prager EM, Johnson LR. Stress at the synapse: signal transduction mechanisms of adrenal steroids at neuronal membranes. Sci Signal. (2009) 2:re5. doi: 10.1126/scisignal.286re5

69. Schwabe L, Wolf OT, Oitzl MS. Memory formation under stress: quantity and quality. Neurosci Biobehav Rev. (2010) 34:584-91. doi: 10.1016/j.neubiorev.2009.11.015

70. Arlt W, Stewart PM. Adrenal corticosteroid biosynthesis, metabolism, and action. Endocrinol Metab Clin N Am. (2005) 34:293-313. doi: 10.1016/j.ecl.2005.01.002

71. Makin HLJ, Gower DB. Steroid Analysis. 2nd ed. New York, NY: Springer Dordrecht Heidelberg London (2010).

72. Pavlovic R, Cannizzo FT, Panseri S, Biolatti B, Trutic N, Biondi PA, et al. Tetrahydro-metabolites of cortisol and cortisone in bovine urine evaluated by HPLC-ESI-mass spectrometry. J Steroid Biochem Mol Biol. (2013) 135:30-5. doi: 10.1016/j.jsbmb.2012.12.015

73. Ikegawa S, Hasegawa M, Okihara R, Shimidzu C, Chiba H, Iida T, et al. Simultaneous determination of twelve tetrahydrocorticosteroid glucuronides in human urine by liquid chromatography/electrospray ionization-linear ion trap mass spectrometry. Anal Chem. (2009) 81:10124-35. doi: 10.1021/ac9018632

74. Brownie AC. The metabolism of adrenal cortical steroids. In: James VHT editor. The Adrenal Gland. New York, NY: Raven Press (1992). p. 209-224.

75. Aerts J, Metz JR, Ampe B, Decostere A, Flik G, De Saeger S. Scales tell a story on the stress history of fish. PLoS ONE (2015) 10:e0123411. doi: 10.1371/journal.pone.0123411

76. von Engelhardt NK, Groothuis TGG. Measuring steroid hormones in avian eggs. Ann N Y Acad Sci. (2005) 1046:181-92. doi: 10.1196/annals.1343.015

77. Aerts J, Schaeck M, De Swaef E, Ampe B, Decostere A. Vibrio lentus as a probiotic candidate lowers glucocorticoid levels in gnotobiotic sea bass larvae. Aquaculture (2018) 492:40-5. doi: 10.1016/j.aquaculture.2018.03.059

78. Gröschl M. Current status of salivary hormone analysis. Clin Chem. (2008) 54:1759-69. doi: 10.1373/clinchem.2008.108910

79. Touma C, Palme R. Measuring fecal glucocorticoid metabolites in mammals and birds: the importance of validation. Ann N Y Acad Sci.(2005) 1046:54-74. doi: 10.1196/annals.1343.006

80. Goymann W. Noninvasive monitoring of hormones in bird droppings: physiological validation, sampling, extraction, sexe differences, and the influence of diet on hormone metabolite levels. Ann N Y Acad Sci. (2005) 1046:35-53. doi: 10.1196/annals.1343.005

81. Ruane NM. Komen H. Measuring cortisol in the water as an indicator of stress caused by increased loading density in common carp (Cyprinus carpio). Aquaculture (2003) 218:685-93. doi: 10.1016/S0044-8486(02)00422-2

82. Berkvens CN, Hyatt C, Gilman C, Pearl DL, Barker IK, Mastromonaco GF. Validation of a shed skin corticosterone enzyme immunoassay in the african house snake (Lamprophis fuliginosus) and its evaluation in the eastern massasuaga rattlesnake (Sistrurus catenatus catenatus). Gen Comp Endocrinol. (2013) 194:1-9. doi: 10.1016/j.ygcen.2013. 08.011

83. Bortolotti GR, Marchant TA, Blas J, German T. Corticosterone in feathers is a long-term, integrated measure of avian stress physiology. Funct Ecol. (2008) 22:494-500. doi: 10.1111/j.1365-2435.2008. 01387.x 
84. Koren L, Mokady O, Karaskov T, Klein J, Koren G, Geffen E. A novel method using hair for determining hormonal levels in wildlife. Anim Behav. (2002) 63:403-6. doi: 10.1006/anbe.2001.1907

85. Bekhbat M, Glasper ER, Rowson SA, Kelly SD, Neigh GN. Measuring corticosterone over a physiological dynamic range in female rats. Physiol Behav. (2018) 194:73-6. doi: 10.1016/j.physbeh.2018.04.033

86. Rettenbacher S, Möstl E, Hackl R, Palme R. Corticosterone in chicken eggs. Ann N Y Acad Sci. (2005) 1046:193-203. doi: 10.1196/annals.1343.016

87. Hackl R, Bromundt V, Daisley J, Kotrschal K, Möstl E. Distribution and origin of steroid hormones in the yolk of Japanese quail eggs (Coturnix coturnix japonica). J Comp Physiol B (2003) 173:327-31. doi: 10.1007/s00360-003-0339-7

88. Arya SK, Dey A, Bhansali S. Polyaniline protected gold nanoparticles based mediator and label free electrochemical cortisol biosensor. Biosens Bioelectron. (2011) 28:166-73. doi: 10.1016/j.bios.2011.07.015

89. Ge Y, Turner APF. Too large to fit? Recent developments in macromolecular imprinting. Trends Biotechnol. (2004) 26:218-24. doi: 10.1016/j.tibtech.2008.01.001

90. Baggiani C, Baravalle P, Giovannoli C, Anfossi L, Giraudi G. Molecularly imprinted polymers for corticosteroids: analysis of binding selectivity. Biosens Bioelectron. (2010) 26:590-5. doi: 10.1016/j.bios.2010.07.023

91. Moreno-Guzmán $\mathrm{M}$, Eguílaz $\mathrm{M}$, Campuzano $\mathrm{S}$, González-Cortés A, Yáñez-Sedeño P, Pingarrón JM. Disposable immunosensor for cortisol using functionalized magnetic particles. Analyst (2010) 135:1926-33. doi: $10.1039 / \mathrm{c} 0 \mathrm{an} 00206 \mathrm{~b}$

92. Carvalho VM. The coming of age of liquid chromatography coupled to tandem mass spectrometry in the endocrinology. J Chrom B Anal Tech N Biomed Life Sci. (2012) 883:50-8. doi: 10.1016/j.jchromb.2011. 08.027

93. Stanley SMR, Wilhelmi BS, Rodgers JP. Comparison of immunoaffinity chromatography combined with gas chromatography-negative ion chemical ionization mass spectrometry and radioimmunoassay for screening dexamethasone in equine urine. J Chromatogr. (1993) 620:250-3. doi: 10.1016/0378-4347(93)80012-S
94. Pujos E, Flament-Waton MM, Paisse O, Grenier-Loustalot MF. Comparison of the analysis of corticosteroids using different techniques. Anal Bioanal Chem. (2005) 381:244-54. doi: 10.1007/s00216-004-2890-9

95. Antignac JP, Monteau F, Négriolli J, André F, Le Bizec B. Application of hyphenated mass spectrometric techniques to the determination of corticosteroid residues in biological matrices. Chromatographia (2004) 59:S13-22. doi: 10.1365/s10337-003-0179-3

96. Antignac JP, Brosseaud A, Gaudin-Hirret I, André F, Le Bizec B. Analytical strategies for the direct mass spectrometric analysis of steroid and corticosteroid phase II metabolites. Steroids (2005) 70:205-16. doi: 10.1016/j.steroids.2004.11.009

97. Kushnir MM, Rockwood AL, Roberts WL, Yue B, Bergquist J, Meikle AW. Liquid chromatography tandem mass spectrometry for analysis of steroids in clinical laboratories. Clin Biochem. (2011) 44:77-88. doi: 10.1016/j.clinbiochem.2010.07.008

98. EN ISO/IEC 17025 General Requirements for the Competence of Testing and Calibration Laboratories. CEN/CENELEC (2005).

99. Commission Decision No. 2002/657/EC. Concerning the Performance of Analytical Methods and the Interpretation of Results. Offical Journal of European Communities (2002).

100. Council Directive 96/23/EC. On Measures to Monitor Certain Substances and Residues Thereof in Live Animals and Animal Products. Offical Journal of European Communities L. (1996).

Conflict of Interest Statement: The author declares that the research was conducted in the absence of any commercial or financial relationships that could be construed as a potential conflict of interest.

Copyright (c) 2018 Aerts. This is an open-access article distributed under the terms of the Creative Commons Attribution License (CC BY). The use, distribution or reproduction in other forums is permitted, provided the original author(s) and the copyright owner(s) are credited and that the original publication in this journal is cited, in accordance with accepted academic practice. No use, distribution or reproduction is permitted which does not comply with these terms. 